\title{
Modéliser la myopathie myofibrillaire pour élucider la pathogenèse cardiaque
}

\author{
Yeranuhi Hovhannisyan, Maria Kitsara, Alexandre Simon, Dorota Jeziorowska, \\ Ekaterini Kordeli, Pierre Joanne, Onnik Agbulut
}

Les myopathies myofibrillaires (MFM) forment un groupe hétérogène de maladies musculaires sévères qui affectent le muscle strié squelettique et/ou le myocarde [1]. Dans de groupe de myopathies, les desminopathies, myopathies myofibrillaire liées à une mutation du gène de la desmine (DES) sont fréquentes. La desmine est le filament intermédiaire spécifique du muscle, un des acteurs du cytosquelette et de l'architecture de la cellule musculaire striée. Parmi toutes les mutations de la desmine induisant une MFM, certaines sont plus spécifiquement à l'origine des affections cardiaques induisant une insuffisance cardiaque sévère et des troubles du rythme. Or, les mécanismes cellulaires à l'origine de la composante cardiaque de cette pathologie restent très mal compris alors même que les atteintes cardiaques sont la cause majeure de mortalité de ces patients. À ce jour, des traitements médicamenteux ou des dispositifs cardiaques implantables sont proposés pour minimiser les dommages liés à cette maladie cardiaque progressive et handicapante. De nouvelles stratégies de recherche pouvant conduire au développement de traitements innovants sont donc fortement désirées.

Pour cela, notre objectif est d'étudier l'impact de différentes mutations de la desmine sur l'organisation structurelle et la fonction des cellules musculaires contractiles du cœur : les cardiomyocytes. Afin de modéliser les affections cardiaques des desminopathies, nous proposons deux approches in vitro basées sur: 1) la génération de cellules souches induites à la pluripotence issues de patients porteurs d'une mutation DES [2] ; 2) l'expression de la desmine sauvage ou mutée par l'utilisation d'un virus adéno-associé (AAV) dans des cardiomyocytes de rats nouveau-nés [3] (Figure 1).

De plus, pour imiter l'organisation anisotrope des cardiomyocytes in vivo, nous avons développé des supports de culture cellulaire comportant des micromotifs obtenus grâce à la technique de l'impression par microcontact qui permet de déposer précisément de fines bandes de gélatine sur des lamelles de verre [4]. Nos résultats ont démontré l'avantage de ce support de culture à micro-motifs par rapport à une boîte de culture standard. Ainsi, les cardiomyocytes ensemencés sur des bandes de gélatine s'alignent les uns par rapport aux autres et présentent une morphologie longitudinale avec une structure sarcomérique bien organisée, prouvant ainsi la pertinence de ce modèle pour l'étude des défauts de structure des cardiomyocytes porteurs des mutations de la desmine. L'organisation structurelle de nos modèles cellulaires est en cours d'évaluation par immunomarquage de marqueurs protéiques des compartiments cellulaires des cardiomyocytes (myofibrilles, réticulum sarcoplasmique et disques intercalaires). Les résultats préliminaires suggèrent que les mutations de la desmine impliquées dans les MFM induisent une perturbation de l'organisation des sarcomères. Notre prochain objectif est d'explorer les perturbations fonctionnelles causées par les mutations de la desmine à l'aide de ces modèles cellulaires innovants.

Cardiac cell modeling of myofibrillar myopathy to elucidate cardiac pathogenesis

\section{LIENS D'INTÉRÊT}

Les auteurs déclarent n'avoir aucun lien d'intérêt concernant les données publiées dans cet article.

\section{RÉFÉRENCES}

1. Béhin A, Salort-Campana E, Wahbi K, et al. Myofibrillar myopathies: state of the art, present and future challenges. Rev Neurol $2015 ; 171: 715-29$.

2. Lian X, Zhang J, Azarin SM, et al. Directed cardiomyocyte differentiation from human pluripotent stem cells by modulating Wnt/ $\beta$-catenin signaling under fully defined conditions. Nat Protoc $2013 ; 8: 162-75$.

3. Joanne P, Chourbagi O, Hourdé C, et al. Viral-mediated expression of desmin mutants to create mouse models of myofibrillar myopathy. Skelet Muscle $2013 ; 3: 4$.

4. Rape AD, Guo WH, Wang YL. The regulation of traction force in relation to cell shape and focal adhesions. Biomaterials 2011; $32: 2043-51$ 

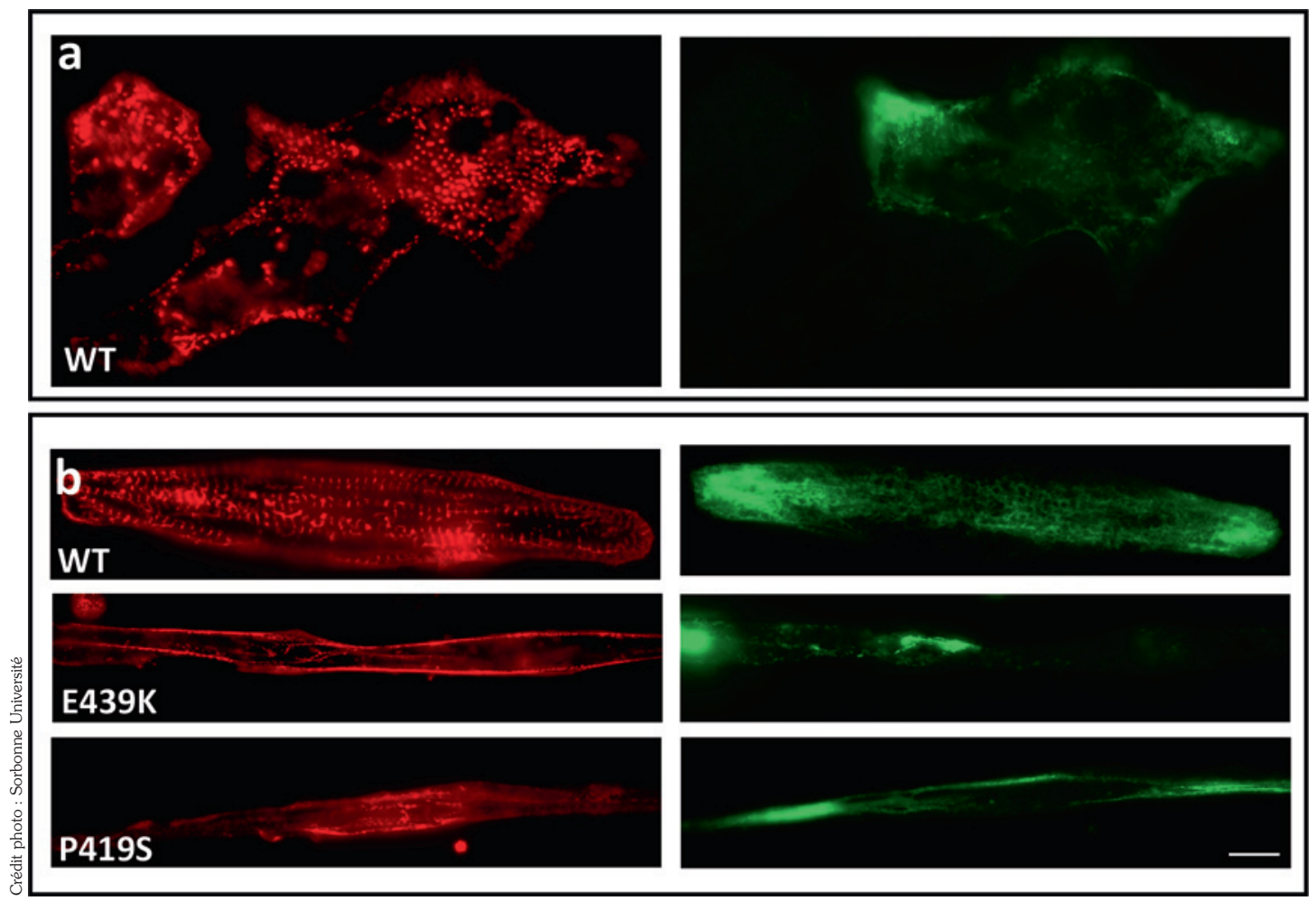

Figure 1

Observation en microscopie à fluorescence de cardiomyocytes dérivés de cellules souches pluripotentes obtenues à partir de patients. Les cardiomyocytes sont cultivés dans des boîtes de cultures classiques (a) ou sur des motifs en ligne de gélatine (b) pour favoriser la structuration du matériel contractile de la cellule. Nos résultats démontrent l'avantage de cette méthode de culture puisque les cardiomyocytes issus d'individus contrôles (WT) présentent une structure sarcomérique mieux organisée. De plus, nous observons des perturbations morphologiques dans les cardiomyocytes des patients porteurs des mutations $\mathrm{E} 439 \mathrm{~K}$ et P419S. Immunomarquage de l' $\alpha$-actinine (en rouge), de la desmine (en vert). Barre d'échelle $=10 \mu \mathrm{m}$.

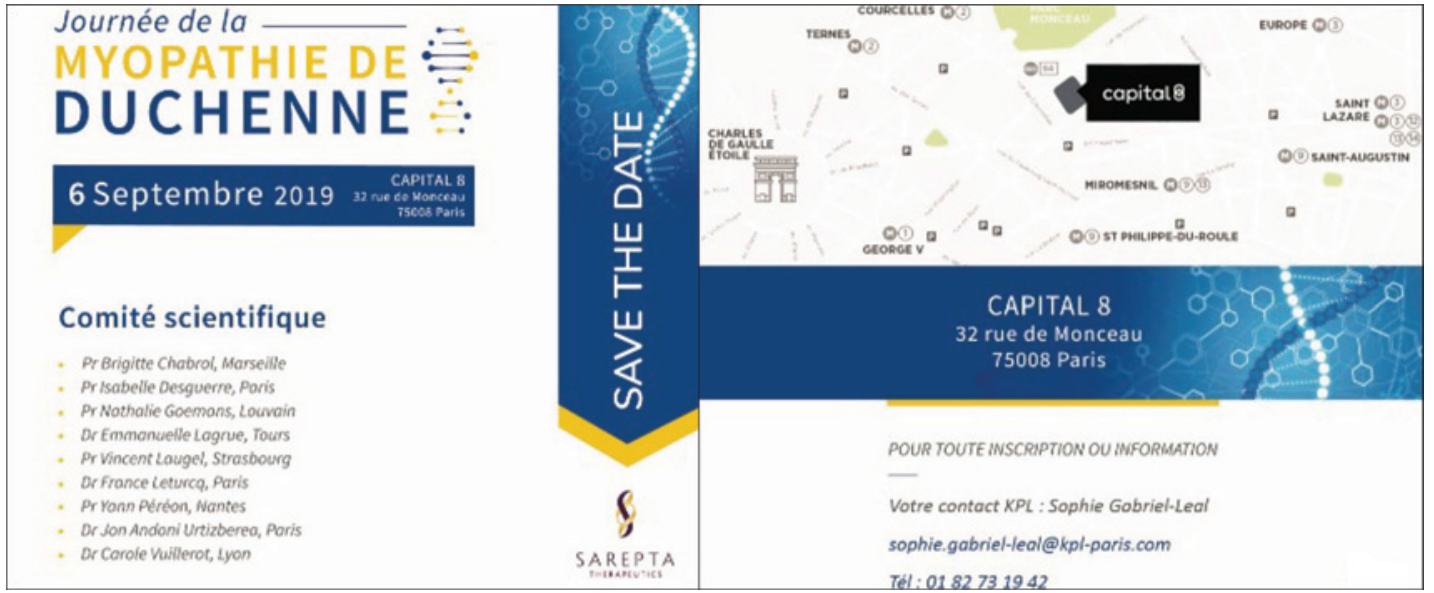

